\title{
The Utility of the Bering Sea and East Asia Rules in Long-Range Forecasting
}

\author{
Joseph S. Renken, ${ }^{1}$ Joshua J. Herman, ${ }^{2}$ Travis R. Bradshaw, ${ }^{3}$ \\ Patrick S. Market, ${ }^{4}$ and Anthony R. Lupo ${ }^{5}$ \\ ${ }^{1}$ KOPN Radio, 915 Broadway St., Columbia, MO 65203, USA \\ ${ }^{2}$ University of Wisconsin-Fox Valley, 1478 Midway Road, Menasha, WI 54952, USA \\ ${ }^{3}$ Moberly Area Community College, 601 Business Loop 70 West, Columbia, MO 65203, USA \\ ${ }^{4}$ Atmospheric Science Program, School of Natural Resources, University of Missouri, 331 ABNR, Columbia, MO 65211, USA \\ ${ }^{5}$ Atmospheric Science Program, School of Natural Resources, University of Missouri, 302 ABNR, Columbia, MO 65211, USA
}

Correspondence should be addressed to Anthony R. Lupo; lupoa@missouri.edu

Received 10 February 2017; Revised 2 August 2017; Accepted 22 August 2017; Published 22 October 2017

Academic Editor: Yoshihiro Tomikawa

Copyright (C) 2017 Joseph S. Renken et al. This is an open access article distributed under the Creative Commons Attribution License, which permits unrestricted use, distribution, and reproduction in any medium, provided the original work is properly cited.

Using the National Center for Atmospheric Research/National Centers for Environmental Prediction (NCAR/NCEP) reanalyses and the daily Pacific North American (PNA) index values from the Climate Prediction Center from 1 January 1950 to 31 December 2016, the utility of the Bering Sea Rule (BSR) and the East Asia Rule (EAR) for making forecasts in the two-to-four-week time frame for the central USA region is examined. It is demonstrated using autocorrelation and Fourier transforms that there may be a degree of predictability in this time frame using the PNA, another teleconnection index, or some variation of them. Neither the BSR nor EAR based forecasts showed skill over climatology in the traditional sense, but using signal detection techniques these indexes were skillful at predicting the onset of anomalous temperature conditions (greater than two standard deviations) in the central USA. The BSR generally produced better results that the EAR and formulae for each index are proposed. Three case studies demonstrate the efficacy of these indexes for forecasting temperatures in the central USA. Then, it is proposed that the success of these indexes is likely due to a strong, quasistationary, and persistent Rossby wave train in the Pacific teleconnection region.

\section{Introduction}

Short- and long-range weather forecasting have improved dramatically over the years (e.g., [1-4]). Short-range forecasts are routinely issued for as long as seven to ten days. Longrange forecasts are issued routinely at least once a month for 30- and 90-day periods for more than a year in advance [5]. Short-range forecasting is an initial value problem performed within the framework of the primitive equations whether the forecasts are made using observations or with the aid of numerical models. Long-range forecasting (LRF) is a boundary value problem that relies on a variety of methods for their construction including statistical methods (e.g., [1, 2]). A list of methods used in LRF include persistence, model of the day, contingency, analogues, or more sophisticated statistical methodologies, and even numerical models. There are also medium range products available through the CPC in the 8-14-day range [6].

Dynamic weather forecasting using numerical models can be done reliably out to approximately seven days but has an absolute limit of about 10-14 days [7, 8]. This limit is a function of the size and rotation rate of the planet as well as the gasses that make up our atmosphere. Limitations for dynamic weather are due also to the lack of data, knowledge of the physical processes, and measurement error (e.g., $[9,10])$. Error in the initial and/or boundary conditions can render model forecasts useless in as quickly as a few days [8], or alternatively two forecasts with slight difference in the initial conditions could evolve in radically different ways over the course of time (e.g., [11, 12]). This problem is referred to 
as sensitivity to the initial conditions (SDOIC). One way to mitigate SDOIC or qualitatively evaluate this problem is ensemble forecasting, and these products have been available routinely for more than two decades [13-15].

Forecasting beyond two weeks can be made dynamically in order to provide statistical guidance $[5,6]$. However, in some cases, daily forecasts available to the general public are published up to 45 or even 90 days in advance. Forecasts in the three-to-four-week time frame have been developed recently and CPC makes this experimental product available for use to the community [16]. Traditionally, there have not been forecasts available for this particular time period.

The Bering Sea Rule (BSR) and East Asia Rule (EAR) are two observationally based teleconnections used by weather forecasters. The former was introduced in 2011, while the latter has been used since at least the 1940s. Both are based Pacific Ocean region teleconnectivity defined statistically by [17]. For example, the Pacific North American (PNA) pattern is associated with four centers of action manifest as an alternating trough-ridge pattern from the Central Pacific to the East Coast of the United States. A ridge-trough pattern from west to east over North America is referred to as a positive PNA configuration, while the opposite pattern is a negative PNA. Occasionally, PNA patterns with more than four centers of action are found over the region (e.g., [18, 19]). Teleconnection is thought to be the result of downstream propagation of Rossby wave activity in the North and South Pacific basins (e.g., $[20,21]$ and references therein). The Bering Sea Region is close to one of the teleconnective centers in the PNA [16], which may allow this rule to be a useful indicator of weather downstream.

Atmospheric blocking, which generally persists for seven to ten days, has also been associated with downstream influences on North America's weather (e.g., [22-24]). Blocking can have a substantial impact on the conditions over a region for an entire month or even a season as many researchers have demonstrated (e.g., [22-30]). Blocking in the East Pacific Ocean Basin is generally associated with a trough over the middle part of the USA (e.g., [22,30]), and a dramatic recent example occurred during November 2014 to be studied here. Also, $[31,32]$ demonstrated the influence of sea surface temperatures associated with El Niño and Southern Oscillation (ENSO) on the predominant temperature and precipitation regimes of the central USA. Additionally, [32] showed that the temperature and precipitation regimes of the Central United States are modified by longer-term variability such as the Pacific Decadal Oscillation (PDO).

Thus, the goal of this research is to demonstrate the utility of the BSR and/or the EAR and show that they have statistical value beyond climatology for prediction of temperature in the period of 7 to 30 days for the United States. This skill is especially measurable in forecasting events that were two or more standard deviations above or below climatology. The construction of both the BSR and EAR Indexes is based on PNA region teleconnectivity, which will be demonstrated in Section 4. Further, this work will show that Pacific Region blocking has a strong correlation to weather and climate in the middle part of the USA, via the impact on the teleconnection patterns in the PNA region, supporting earlier work (e.g., $[27,29,31,32])$. Finally, case studies will be presented in order to demonstrate the use and capabilities of these indexes. We will also demonstrate that there is a strong degree of autocorrelation in the two-to-four-week time frame by examining the PNA index. Section 2 will define the BSR and EAR and show the data and methods used, and Section 3 will examine the teleconnectivity in the PNA region and blocking. Section 4 will demonstrate the skill of the BSR and EAR, propose an index, examine case studies, and provide a discussion of the results.

\section{Data and Methods}

2.1. Data. The data used for this research comes from a variety of sources, including the National Centers for Environmental Prediction/National Centers for Atmospheric Research (NCEP/NCAR) reanalyses [29]. We also used the National Climactic and Data Center (NCDC) climatic information (teleconnections and climatological information such as surface temperatures). The NCEP/NCAR reanalysis data used were the $500 \mathrm{hPa}$ height fields on a $2.5^{\circ} \times 2.5^{\circ}$ latitude/longitude grid four times daily from 1948 till present. The daily PNA index information was also available through the Climate Prediction Center (CPC) website (derived from the NCEP/NCAR reanalyses) from 1 January 1950 to 31 December 2016 (a 67-year period).

2.2. Methods and Definitions. The BSR uses $500 \mathrm{hPa}$ heights observed in the Bering Sea Region and three points in the USA, which show strong correlation to each other. This means low $500 \mathrm{hPa}$ height anomalies in the Bering Sea Region occurring concurrently with low $500 \mathrm{hPa}$ height anomalies at the three points in the USA or high $500 \mathrm{hPa}$ height anomalies in the Bering Sea Region occurring concurrently with high $500 \mathrm{hPa}$ height anomalies in the USA. In the USA, the low $500 \mathrm{hPa}$ height anomalies would be associated with colder than normal surface temperatures, and the high $500 \mathrm{hPa}$ height anomalies would be associated with warmer than normal surface temperatures (e.g., $[17,18])$. These three points are in southern Utah, Western MO, and near Long Island, using a similar methodology to [17]. The primary correlation time period is for two to four weeks. The EAR correlates $500 \mathrm{hPa}$ heights in East Asia to these same points in the USA, and the primary time scale for this index is one to two weeks. Initially, a value for BSR and EAR was not calculated. They were examined qualitatively by identifying the concurrent existence of positive (negative) anomalies in each region. The formula for each and a rationale for their development will be proposed in the results section.

The forecast verification method was based on the methods used in [3] and borrowed from [31] and can be described as a skill score. The formula is

$$
\text { Skill }=\frac{(\text { Forecast }- \text { Base })}{(\text { Verification }- \text { Base })},
$$

where "base" is a baseline forecast typically climatology or some other benchmarks. "Forecast" is the projected value. Then both are converted into a point system based on the difference from "verification" (observed variable). For 
TABLE 1: The contingency table for BSR and EAR forecasts of $2 \sigma$ events and observations.

\begin{tabular}{lcc}
\hline Observed (below)/forecast (right) & Yes & No \\
\hline Yes & $X$ & $Y$ \\
No & $Z$ & $W$ \\
\hline
\end{tabular}

example, from [3] and using temperature information in (1), a forecast within $+/-2^{\circ} \mathrm{F}$ of the observed was considered perfect ( 2 points). A forecast within $+/-2$ to $+/-4^{\circ} \mathrm{F}$ was given 1 point, and 0 was given to forecasts outside the $4^{\circ} \mathrm{F}$ range. Here we modified this scoring system by awarding two, one, and zero point(s), respectively, for a forecast that was within one, one to two, or more than two monthly standard deviation $(\mathrm{s})(\sigma)$, respectively, away from observations. This scoring procedure is similar to that used by [27] for seasonal predictions. Here, climatology is the "base" forecast.

The EAR and BSR temperature forecasts were initially tested using a 7-11- and 17-21-day forecast, respectively. A quick analysis (August 2013-November 2014, not shown) demonstrated that the skill scores for the BSR and EAR forecasts were similar for the 16-month period as well as within each season (not shown). Thus, initially it appeared that neither method added value over climatology. Also, each method produced a similar number of perfect forecasts (two points, $27 \mathrm{BSR}, 24 \mathrm{EAR}$, and 21 climatology, resp.) and busted forecasts (zero points, 16 climatology, $17 \mathrm{BSR}$, and $18 \mathrm{EAR}$, resp.). Thus, it is apparent that climatology is difficult to improve upon since temperature data is normally distributed. A forecast based on climatology in theory would result in a theoretical score of 1.63 out of 2.00 points ( 2 points, 1 point, and 0 points for $68 \%, 27 \%$, and $5 \%$ of forecasts, respectively).

However, anecdotal evidence indicated that the BSR and EAR performed well when the observed temperatures were greater than $2 \sigma$ from the normal, and a longer study period of BSR and EAR forecasts is shown in Section 4. Scoring these forecasts based on skill as shown in (1) only may not be the correct way to demonstrate value beyond climatology. This, however, does not preclude forecast improvement via dynamical forecasting. Additionally, forecasts that involved one point scored (1-2 $\sigma$ ) can be considered partial successes, but there are more contingencies that would fit into this type of analysis.

Thus, (signal) detection theory was borrowed from the National Weather Service and others, typically used in shortrange forecasting of severe weather occurrence (e.g., [33]). It is based on a contingency table for weather events forecast and observed (e.g., [34] and Table 1). Using this methodology will allow for the scoring of the BSR and EAR versus climatology, demonstrating value in abnormal $(2 \sigma)$ weather conditions. From signal detection theory (Table 1), $X$ is the number of $2 \sigma$ events that were forecast correctly and occurred (two points), and $Y$ is the number of events not forecast but did occur (zero points, no BSR or EAR anomaly). The value $Z$ is the number of forecasted events that did not occur (zero points, BSR or EAR anomaly of the wrong sign), and $W$ is the number of events that did not occur and not forecast (two points) (Table 1). Here we calculate forecast success or probability of detection (POD, (2a)), false alarm rate (FAR, (2b)), success ratio (SRO, (2c)), critical success (CSI, (2d)), correct negatives (CRN, (2e)), failures (FFR, (2f)), and Bias (BIAS, $(2 \mathrm{~g})$ ):

$$
\begin{aligned}
\mathrm{POD} & =\frac{X}{(X+Y)}, \\
\mathrm{FAR} & =\frac{Z}{(X+Z)}, \\
\mathrm{SRO} & =\frac{X}{(X+Z)}, \\
\mathrm{CSI} & =\frac{X}{(X+Y+Z)}, \\
\mathrm{CRN} & =\frac{W}{(W+Y)}, \\
\mathrm{FFR} & =\frac{Y}{(W+Y)}, \\
\mathrm{BIAS} & =\frac{(X+Z)}{(X+Y)} .
\end{aligned}
$$

In order to determine whether the BSR or EAR $2 \sigma$ forecasts produced signal above the background noise, the sensitivity index $\left(d^{\prime}\right)$ is used to determine whether there is separation between the distribution of the signal and the noise $[35,36]$. If the value of value of $\left(d^{\prime}\right)$ is zero or very low then the signal cannot be detected readily above the noise and the result is pure chance. Then $\left(d^{\prime}\right)$ is calculated as follows [36]:

$$
d^{\prime}=z(\mathrm{POD})-z(\mathrm{FAR}),
$$

where $z$ (POD) and $z$ (FAR) are the $z$-scores that correspond to the probabilities associated with POD and FAR. This will result in a measure of statistical significance.

2.3. Blocking Definition. The definition of a blocking event used here can be found in [23] and references therein, and all Northern Hemisphere events occurring since 1 July 1968 are archived at [37]. Many studies have used this definition, and one of the latest is [29]. We use block occurrence and days here and the definition is described briefly as in [38]. The blocking criterion was initially developed in [39] and modified to be automated by [23]. This criterion determines an onset and termination times for each blocking event using the $500 \mathrm{hPa}$ height maps, and each event was subdivided into onset, intensification, maintenance, and decay stages (e.g., $[25,26,39])$. Onset is the period before the block formation, while intensification (decay) is represented by a general increase (decrease) in center point $500 \mathrm{hPa}$ height values. Maintenance is represented generally by periods where the 


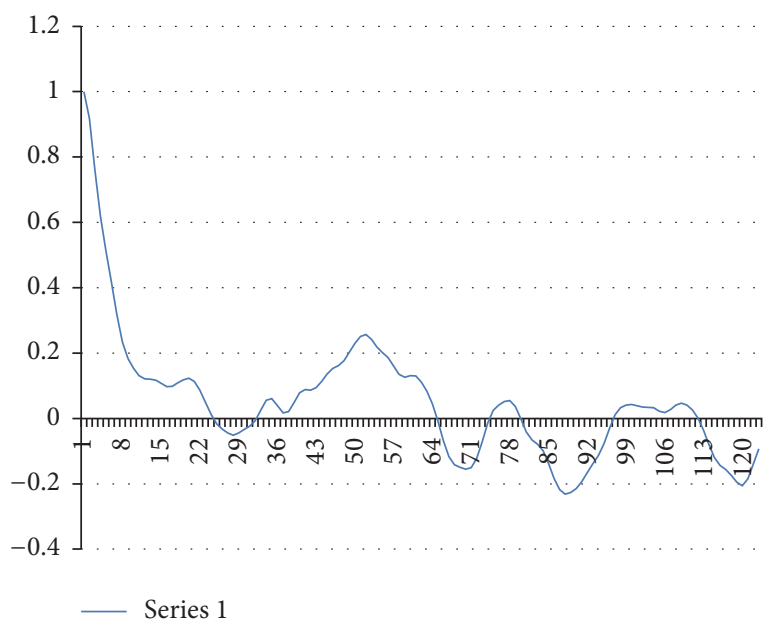

(a)

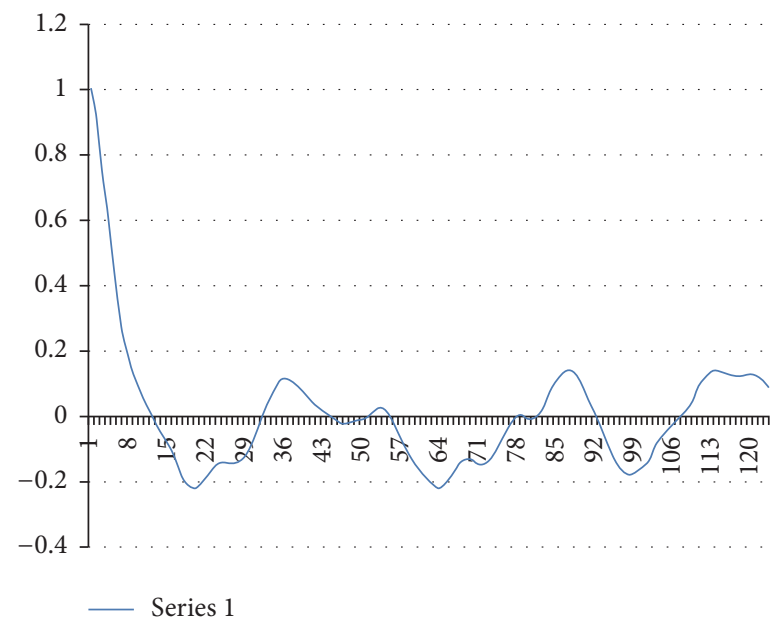

(b)

Figure 1: The autocorrelation of the PNA index from (a) 1 January 2012 to 31 December 2013 and (b) from 1 January 1955 to 31 December 1956.

magnitude of the center point time evolution is close to zero. In brief, these studies employ a combined and extended set of conditions set forth earlier by the subjective definition of [40] and the objective criterion of [41]. An event had to persist for five or more days [41], however, rather than ten days as proposed by [40]. Lastly [23] defined the Pacific (Atlantic) Region as the area bounded by $140^{\circ} \mathrm{E}-100^{\circ} \mathrm{W}\left(80^{\circ} \mathrm{W}-40^{\circ} \mathrm{E}\right)$.

2.4. Teleconnections. The definitions for the teleconnections examined here were identical to the work of [17] or definitions found on the NWS and CPC websites. Here we examined the East (West) Pacific Oscillations (EPO [WPO]), the North Pacific Oscillation (NPO), the PNA, the North Atlantic Oscillation (NAO), and the Arctic Oscillation (AO) and extracted the information. All correlations statistics were tested for significance using standard methods, which can be found in any elementary statistics textbook [e.g., [42]]

Finally, in order to determine if there was predictability in the PNA index time series, autocorrelation was performed by lagging the PNA index by as much as 130 days for twoyear periods from 1 January 1950 to 31 December 2016. Autocorrelation can be used in order to test for chaotic or cyclical behavior in a data set (e.g., [43]) and has been used in other disciplines such as economics (e.g., [44]). If a system has limited predictability, then the autocorrelation will fall to zero with further lag times and remain there. If there is cyclical behavior, autocorrelation will increase near the time scale of the forcing function. Additionally, the entire time series for the PNA index was decomposed using Fourier series in order to isolate significant power in the time series.

\section{Analysis of Pacific Region Teleconnectivity}

3.1. $500 \mathrm{hPa}$ Height Periodicity. The PNA index derived from the $500 \mathrm{hPa}$ height field using autocorrelation for two-year periods from 1950 till present was tested for periodicity and a representative sample is shown in Figure 1(a) (2012-2013). The autocorrelation falls rapidly to near zero, but then increases around 20 and 34 days. There is also a strong nonzero peak found in the 50-55-day period. Examining all other biennial time periods in the 67-year data set revealed that these graphs were all similar in form but that the peaks may be of different amplitude or shifted to a longer or shorter period (Figure 1(b)). While this test hints at limited predictability in the three-to-four week time frame and beyond, this test by itself cannot identify recurrence. Additionally, the periods shown in Figure 1 are a small segment of the climatological record for the PNA region.

Next, the time series of the daily PNA index for the entire 67 -year period was converted to wave space using Fourier decomposition (Figure 2). The entire set of wave numbers is shown here, but the time period in question in highlighted. The spectral decomposition shows peaks at several wave numbers, and the period can be determined by dividing the wave number of the spectral peak by the length of the data set. For example, in addition to spectral peaks associated with the annual cycle there were strong peaks around wave numbers 505,570 , and 610 , corresponding to a period of about 47 , 42 , and 39 days (Figure 2). These peaks probably correspond to a quasistationary Rossby wave train (e.g., [20, 45-47]) or Kelvin waves associated with the Madden Julian Oscillation (MJO) and the midlatitude jetstream (e.g., [48, 49]). The analysis here cannot determine if the peaks identified above are forced by which process. It is more likely the same peak whose period may be modulated by the annual cycle, ENSO, PDO, MJO, or climate trends. The latter may be the case when testing different parts of the 67-year time series using autocorrelation. It is conceded that further analysis would be needed to verify this assertion.

The two-to-three-week period of interest is shown in Figure 2(b), which shows wave numbers 1000 to 1500 (waves (67 year $\left.^{-1}\right)$ ) on the abscissa, and these correspond to periods of 24 to 16 days. There are statistically significant spectral peaks found near 1040-1060 (waves $\left(67\right.$ year $\left.^{-1}\right)$ ), in the 1140-1170 


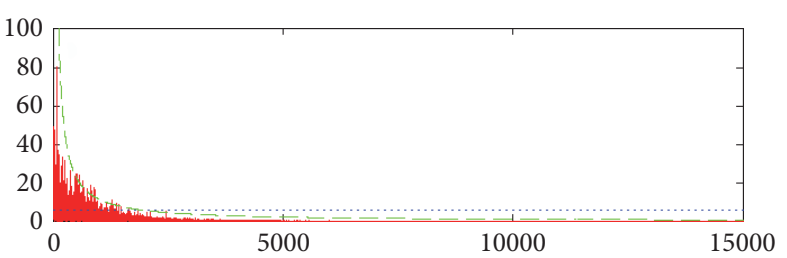

(a)

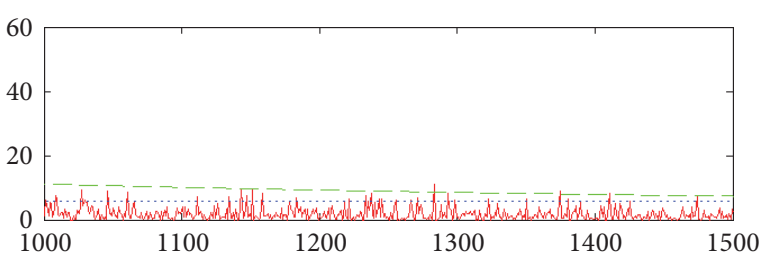

(b)

FIGURE 2: The spectral decomposition of the (a) entire 67-year time series of the PNA index and (b) a subset for 1000-1500 waves corresponding to our time frame. The abscissa is wave number 1000 to 1500 , and the ordinate is spectral power. The (a) green dashed and (b) blue dotted lines are the $95 \%$ confidence level using a red or white noise spectrum, respectively.

TABLE 2: A list of variables that correlate to Pacific or Atlantic Region monthly blocking occurrences and days at three different levels of statistical significance from January 2011 to December 2016.

(a)

\begin{tabular}{lcc}
\hline Variable & Correlation to Pacific blocking & Correlation to Pacific blocking days \\
\hline At $99 \%$ confidence level $(>|0.28|)$ & & -0.35 \\
$\quad$ West Pacific Oscillation & -0.34 & -0.39 \\
$\quad$ Midwest monthly temperature anomaly & -0.32 & 0.24 \\
At $95 \%$ confidence level $(>|0.20|)$ & & 0.25 \\
$\quad$ Atlantic Region blocking & & \\
At $90 \%$ confidence level $(>|0.16|)$ & & \\
$\quad$ None & & \\
\hline
\end{tabular}

(b)

\begin{tabular}{lcc}
\hline Variable & Correlation to Atlantic blocking & Correlation to Atlantic blocking days \\
\hline At $99 \%$ confidence level $(>|0.28|)$ & & -0.35 \\
$\quad$ West Pacific Oscillation & -0.34 & 0.24 \\
At 95\% confidence level $(>|0.20|)$ & & 0.27 \\
$\quad$ Pacific Region blocking & 0.25 & -0.19 \\
NAO & 0.20 & 0.16 \\
At 90\% confidence level $(>|0.16|)$ & & None \\
Midwest monthly temperature anomaly & 0.16 & \\
PNA & & \\
\hline
\end{tabular}

(waves $\left(67\right.$ year $\left.^{-1}\right)$ ), and 1290 (waves $\left(67\right.$ year $\left.^{-1}\right)$ ), which correspond to 23, 21, and 19 days, respectively. This analysis, combined with the autocorrelation, hints at predictability in the two-to-three-week time scale.

3.2. Blocking. All blocking events and blocking days in the Pacific Region and Atlantic Region were compared over a sixyear period from 1 January 2011 to 31 December 2016 with various teleconnection indexes and the monthly temperature and precipitation anomalies. This analysis was done not to establish the connection between the North Pacific and North American weather, which has been shown by many studies ([17-25, 27, 29-32]), but to establish the strength of these teleconnections within the latest six-year period. A list of the teleconnections and monthly temperature correlating to Pacific or Atlantic blocking are shown in Table 2. Pacific Region blocking correlated strongly with the Pacific Basin teleconnection patterns as expected (see Table 2) and central US temperature anomalies. Atlantic Region blocking also correlated with central US temperatures (e.g., [50]) at the
$90 \%$ confidence level. The lack of significance for monthly precipitation anomalies might be expected as these can be influenced by more localized factors as well as large-scale flow regimes. In general, the occurrence of Pacific Region blocking correlated with cooler conditions in the Midwest as shown in some previous studies [27, 29, 30], and this is especially marked in the cold season [30].

Additionally, other teleconnections were significantly correlated during this six-year period and these are NAO and EPO (negatively at the $99 \%$ confidence level) and the AO with the PNA and EPO (negatively at the 95\% confidence level). Thus, there is a strong connection between general circulation features over the Pacific Region with weather and climate over the Midwest region as shown previously by many others. An example of the impact of Pacific Region blocking on Midwest region weather can be demonstrated here. The onset of a strong Pacific Region blocking event on 5 November 2014 encouraged forecasts of cooler than normal temperatures for the remainder of November in the Midwest Region. This blocking event persisted until 17 November. However, even 
TABLE 3: As in Table 1, except for the outcome of BSR/EAR/climatology forecasts.

\begin{tabular}{lcc}
\hline Observed (below)/forecast (right) & Yes & No \\
\hline Yes & $108 / 83 / 0$ & $23 / 53 / 174$ \\
No & $43 / 38 / 0$ & $237 / 237 / 237$ \\
\hline
\end{tabular}

TABLE 4: The calculated performance indicators from (2a)-(2g) for the BSR, EAR expressed as a percentage (times 100) for all events, and then cold events/warms events only.

(a)

\begin{tabular}{lccc}
\hline All events & BSR & EAR & Climatology \\
\hline POD & 82.2 & 61.0 & 0.0 \\
FAR & 28.9 & 31.4 & N/A \\
SRO & 71.1 & 68.6 & N/A \\
CSI & 60.9 & 47.7 & 0.0 \\
CRN & 91.2 & 81.7 & 57.7 \\
FFR & 8.8 & 18.3 & 42.3 \\
BIAS & 115.5 & 89.0 & 0.0 \\
\hline
\end{tabular}

(b)

\begin{tabular}{lccc}
\hline Cold/warm events & BSR & EAR & Climatology \\
\hline POD & $78.0 / 85.2$ & $58.2 / 63.0$ & $0.0 / 0.0$ \\
FAR & $35.0 / 24.2$ & $33.3 / 30.1$ & N/A \\
SRO & $65.0 / 75.8$ & $66.7 / 69.9$ & N/A \\
CSI & $54.9 / 67.0$ & $45.1 / 49.5$ & $0.0 / 0.0$ \\
CRN & $96.9 / 96.3$ & $92.6 / 91.1$ & $72.7 / 74.5$ \\
FFR & $3.1 / 3.7$ & $7.4 / 8.9$ & $17.3 / 25.5$ \\
BIAS & $120.0 / 112.3$ & $87.3 / 80.1$ & 0.0 \\
\hline
\end{tabular}

in mid-October, the 30-day outlook projected a warmer than normal November for the far Northern Tier of states [51] and "equal chances" in the Missouri region. The outcome for November 2014 was a temperature anomaly of $-5^{\circ}$ to $-6^{\circ} \mathrm{F}$ below normal in the central USA. The onset and strengthening of this blocking event were not foreseen but were the result of the development of Super Typhoon Nuri in the west Pacific. Nuri became extratropical and deepened to about $924 \mathrm{hPa}$, which is the strongest North Pacific extratropical cyclone on record. This cyclone strengthened considerably an initially weak blocking event through the mechanism proposed by [25, 26], or [39]. The strong blocking event then forced strong troughing over North America during the week of 10 November.

\section{BSR and EAR Forecasts, Case Studies, and Discussion}

4.1. The Bering Sea and East Asia Rules. In order to examine the BSR and EAR, forecasts were made in the 17-21- and 7-11day time period for the central USA, a 54-month forecast period for the BSR and EAR beginning with 1 January 2013 to 30 June 2017 was archived. This time period included the cold winter of 2013-2014 [52] and expanded on earlier work including the case studies below [53]. Thus, in order to examine the value of the BSR and EAR during extreme events relative to climatology, signal detection theory was used and the results are shown in Tables 3 and 4 .

The results demonstrated that the BSR in general was more successful than the EAR (Table 3), but both showed success in forecasting $2 \sigma$ events (174 total) of two days or longer in duration. For the BSR, there were more correct forecasts (108), than those that were not correct (66). The EAR, however, scored correct forecasts for slightly less than one-half of the events (83). These results were remarkably consistent by season overall (not shown), but individual seasons showed varying rates of success. For example, the BSR was successful in forecasting nine of 11 extreme events for spring 2017.

Table 4 analyzes the BSR, EAR, and climatology forecasts more rigorously. The BSR and EAR show higher scores than climatology in desirable categories (POD, SRO, CSI, and CRN), but smaller FFR rates. The BSR scores were better than the EAR scores and produced a smaller FAR and FFR. This might be expected since the centers of action are closer for the BSR than the EAR in spite of the larger forecast range. Interestingly, the BSR and EAR both performed better in forecasting of warm anomalies versus cold anomalies (Table 4). Thus, the values in Table 4 suggest that both the BSR and EAR outperform climatology for $2 \sigma$ events.

In order to test whether each index could capture the signal above the noise, the sensitivity index $\left(d^{\prime},(3)\right)$ is 
calculated here. For both the BSR and EAR, the POD was larger than the FAR indicating that each index captures a signal above the noise or that the detection of signal is not due to chance. For the BSR, the $d^{\prime}$ was significant at the $90 \%$ confidence level; however, the EAR significance did not rise to that of standard levels tested, a negative outcome for this index. When examining $d^{\prime}$ for the warm and cold BSR events, the detection of warm events was significant at the $95 \%$ confidence level. For detecting cold events, the significance of the BSR was just below the $90 \%$ confidence level.

4.2. The BSR and EAR Formulae. Here we propose teleconnection index formulae for the BSR and the EAR in a manner similar to [17]. They [17] proposed a West Pacific Oscillation (WPO) teleconnection based on the $500 \mathrm{hPa}$ height difference between $60^{\circ} \mathrm{N}$ and $30^{\circ} \mathrm{N}$ along the $155^{\circ} \mathrm{E}$ meridian. This index would be negative under most circumstances, but positive when there was blocking in that sector. This index is useful for diagnosing the strength of the Aleutian Low [17]. The well-known PNA index [17] is associated with four centers of action, two each in the Central Pacific (the northern one at $45^{\circ} \mathrm{N} 165^{\circ} \mathrm{W}$ ) and two over North America (including the Southeast United States at $30^{\circ} \mathrm{N}$ $\left.85^{\circ} \mathrm{W}\right)$. A similar $500 \mathrm{hPa}$ height correlation analysis to [17] was performed here, but using only those stations that launch upper air soundings routinely. The highest correlations were found between $500 \mathrm{hPa}$ heights at Shemya Island $\left(52^{\circ} \mathrm{N}\right.$ and $\left.174^{\circ} \mathrm{W}\right)$ and $500 \mathrm{hPa}$ heights at Springfield, MO (SGF) $\left(37^{\circ} \mathrm{N}\right.$, $93^{\circ} \mathrm{W}$ ) for the BSR. These locations are close to the two positively correlating centers of the PNA index above, and the $500 \mathrm{hPa}$ heights would be related to each other and to surface conditions as described in Section 2.2 (e.g., [17, 18, 29-32]). Thus, we propose a BSR Index (BSRI) as

$$
\mathrm{BSRI}=\frac{1}{2}\left(z^{*}(\text { Shemya })+z^{*}(\mathrm{SGF})\right),
$$

where $z^{*}$ is the $500 \mathrm{hPa}$ height anomaly at each location (m).

For the EAR, the highest correlations were obtained for the $500 \mathrm{hPa}$ heights at Seoul, South Korea $\left(37.5^{\circ} \mathrm{N} 127^{\circ} \mathrm{E}\right)$, and those at Nashville, TN (BNA) $\left(36^{\circ} \mathrm{N}\right.$ and $\left.87^{\circ} \mathrm{W}\right)$. The Asian center is close to the northern center of action of the WPO near the Sea of Okhotsk teleconnection center of action found in [46] or [47]. The BNA station, like the SGF station, is located near the Southeast USA PNA center of action. The formula for the EAR Index (EARI) is

$$
\text { EARI }=\frac{1}{2}\left(z^{*}(\text { Seoul, South Korea })+z^{*}(\text { BNA })\right) .
$$

These formulae will be used in three case studies below. Since these centers of action are positively correlated, a negative (positive) index represents concurrent toughing (ridging) at or near each location.

\subsection{Three Case Studies}

4.3.1. 28 April 2014: Severe Weather. On 28 April 2014, severe weather occurred across the middle southeast USA and the St. Louis, MO region. The Storm Prediction Center (SPC) archived several reports of tornadoes (153), large hail (80), and strong winds (229) (Figure 3(d)). The severe weather was associated with a strong trough at $500 \mathrm{hPa}$ located over the plains states (Figure 3(c)) and was associated with a welldeveloped low pressure at the surface. Examining the Bering Sea Region about 20 days previously (8 April 2014) shows a strong $500 \mathrm{hPa}$ low near the Kamchatka Peninsula and the Aleutians (Figure 3(a)). Table 5 confirms that the BSRI was strongly negative at this time. Figure 3(c) shows a trough in the Bering Sea Region on 28 April, a little east of the trough that was there in Figure 3(a), as well as a negative BSRI (Table 5). Thus there is an approximately two-to-fourweek cycle in the PNA index as demonstrated in Section 3. This case is a successful example of the BSR(I) forecast. About eight days before the 28 April event, a weak low was located over East Asia (Figure 3(b)) which corresponds to the western EAR center and ridging over the central USA. In this case, the BSR(I) performed better than the EAR(I) at 20 days, but the EAR(I) did not indicate troughing at around eight days.

4.3.2. November 2014: Typhoon Nuri. In early November 2014, Typhoon Nuri moved poleward in the western Pacific becoming extratropical and deepening to $924 \mathrm{hPa}$ as the strongest North Pacific cyclone ever [53]. This was reflected in the $500 \mathrm{hPa}$ height field as a strong low over the western Bering Sea (Figure 4(a)) during the 8-10 November 2014 period. This cyclone was upstream of a weak blocking event, which had onset at 1200 UTC 5 November at about $170^{\circ} \mathrm{W}$ (see [54]). The cyclone interacted with the blocking event, strengthening the block through the same mechanism involving upstream cyclones as shown in [22, 25] or [26]. This blocking event induced persistent troughing over North America, which was particularly strong in the middle of and late in the month (Figures 5(b) and 5(c)). In this case, the PNA pattern intensified strongly following the strengthening of a Pacific Region surface cyclone and the blocking event (Figure 4(a)) [53]. As stated in Section 3, temperatures were below normal for the central USA for November, but particularly during the middle and then again at the end of November. During late November, there was also an upstream trough in the Bering Sea Region (Figure 4(c)). The BSRI and EARI were strongly negative in early and midNovember, or at least close to zero in association with these periods (Table 5). This indicated that the late November cold event could be identified strongly (Figure 4(c)) in association with the remnants of Nuri using both indexes from midNovember as well (Table 5). This case represented the success of both indexes [53].

4.3.3. Summer 2012: Heatwave. The previous two examples featured a strong negative anomaly impacting the central USA; however, the BSR (I) and EAR (I) can be used to indicate positive anomalies as well. During the summer of 2012, the central part of the USA endured a warm dry summer that ranked among the top five hottest and driest of all time. The summer season surface temperature was $3^{\circ}-5^{\circ} \mathrm{F}$ above the 30-year normal, and July temperatures were as much as $5^{\circ}-8^{\circ} \mathrm{F}$ greater than the long-term normal. The warmest temperatures were observed from late June through early 


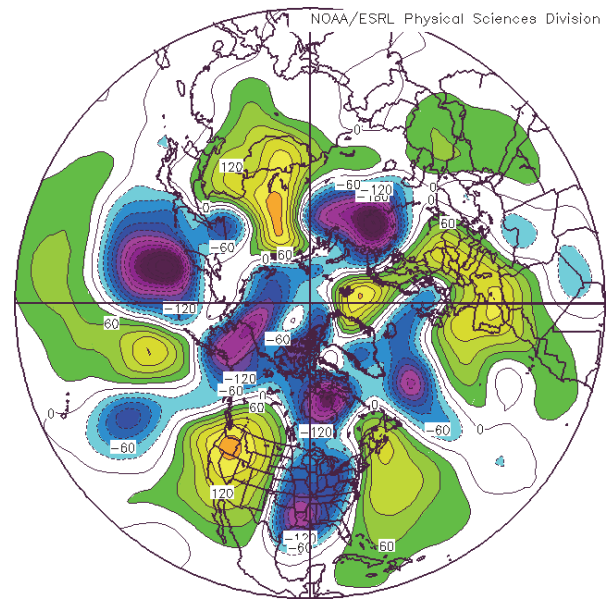

(a)

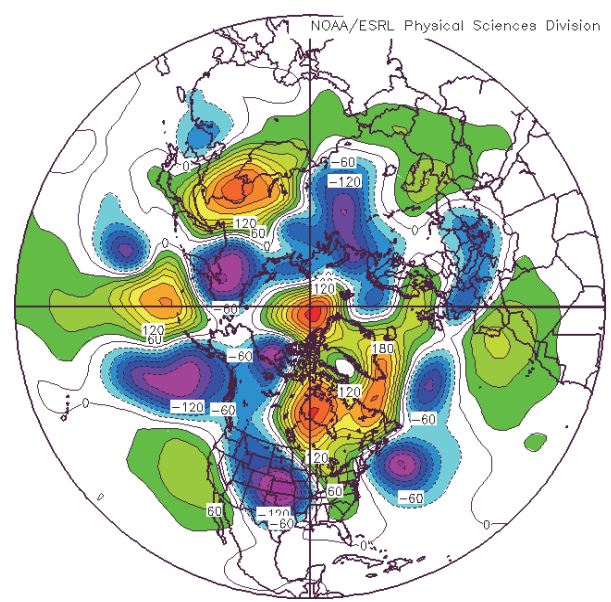

(c)

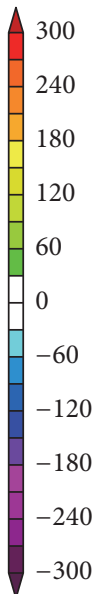

300
240
180
120
60
0
-60
-120
-180
-240
-300

80
20
60
-60
-120
-180
-240
-300

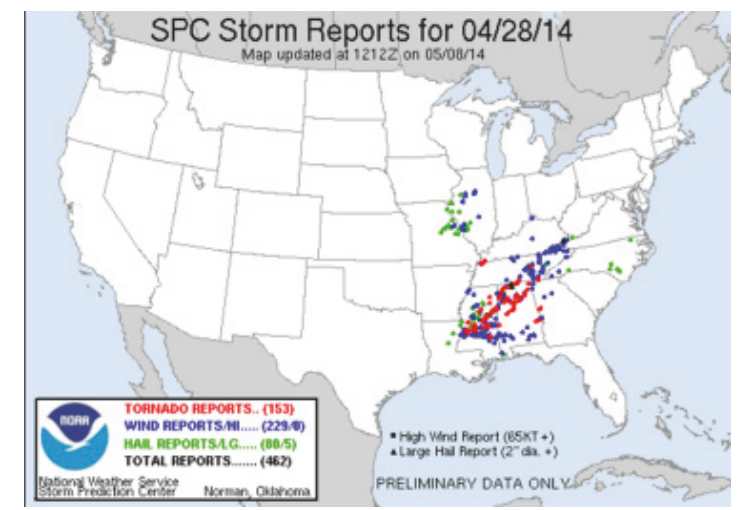

(d)

Figure 3: The 1200 UTC Northern Hemisphere 500 hPa height anomalies versus the 1981-2010 climatology for (a) 8 April 2014, (b) 20 April 2014, and (c) 28 April 2014, respectively, and (d) the Continental USA severe weather reports. The contours in (a), (b), and (c) are every 30 (m).

TABLE 5: The BSRI (m) and EARI (m) calculations for each case study and corresponding to the maps shown in Figures 3-5.

\begin{tabular}{lcc}
\hline Dates & BSRI & EARI \\
\hline 28 April 2014: severe weather & & -63 \\
1200 UTC 8 April 2014 & -111 & +47 \\
1200 UTC 20 April 2014 & +107 & -9 \\
1200 UTC 28 April 2014 & -8 \\
November 2014: Typhoon Nuri & \\
1200 UTC 8-10 November 2014 & -120 \\
1200 UTC 16 November 2014 & -100 & +1 \\
1200 UTC 25-27 November 2014 & -15 \\
Summer 2012: heatwave & \\
1200 UTC 6-16 June 2012 & +33 \\
1200 UTC 20-30 June 2012 & +38 \\
1200 UTC 26 June-6 July 2012 & +40 \\
\hline
\end{tabular}




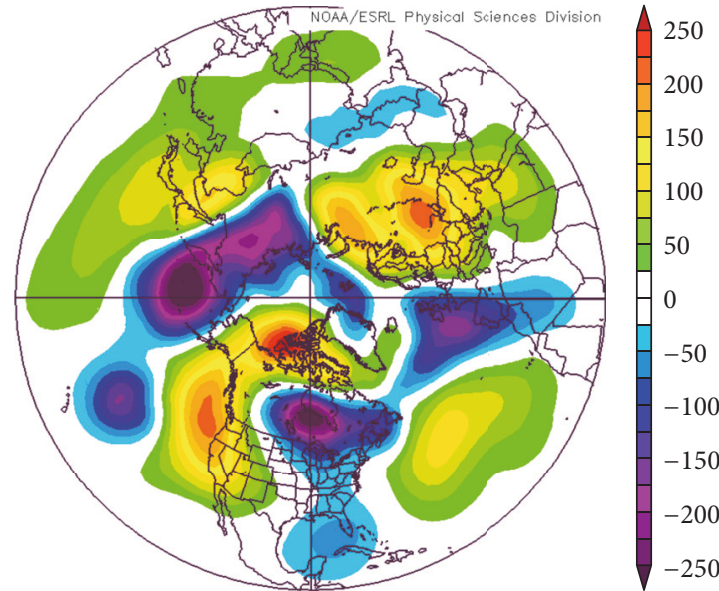

(a)

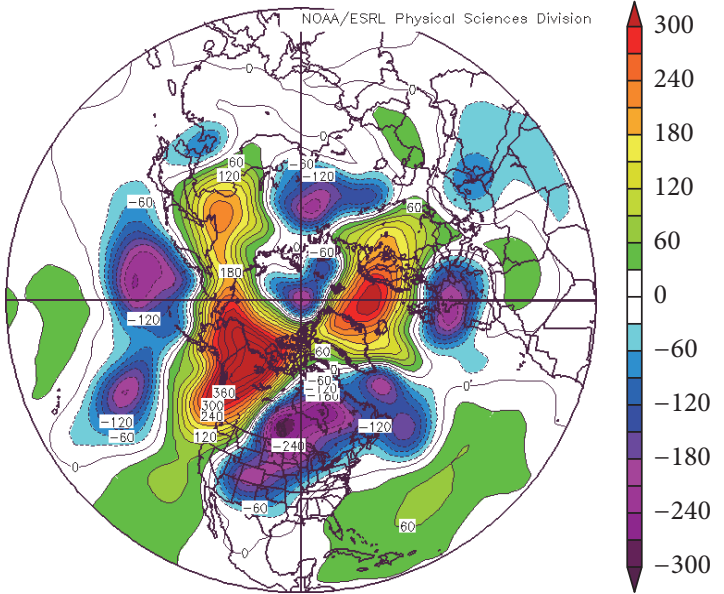

(b)

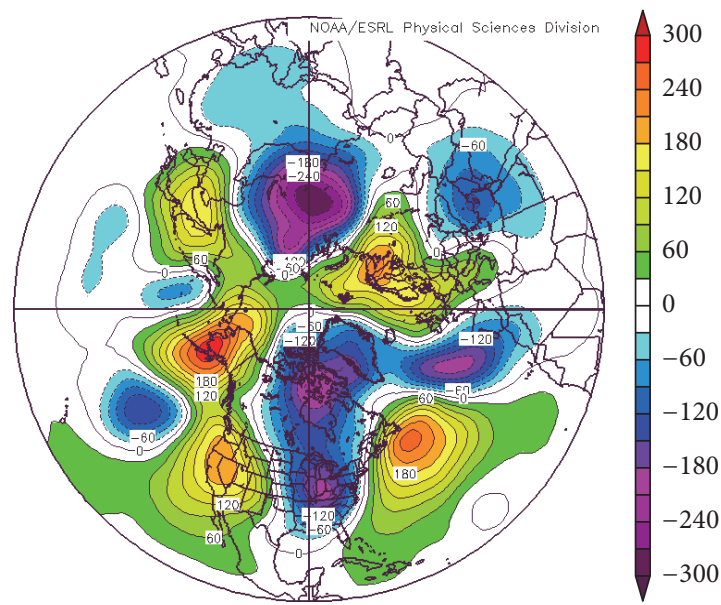

(c)

Figure 4: As in Figures 3(a), 3(b), and 3(c), except for (a) 8-10 November 2014, (b) 16 November 2014, and (c) 25-27 November 2014.

July, when maximum temperatures were greater than $36^{\circ} \mathrm{C}$ during the period of 26 June to 7 July 2012 in the central USA. In this case, eleven-day composites are shown since $500 \mathrm{hPa}$ height anomalies during the hottest part of the summer were strongly positive over the middle of the USA with the strongest positive anomalies located over the western Great Lakes (Figure 5(c)). Three weeks previously, there were weakly positive height anomalies located over the East Asia, the Bering Sea, and central USA region (Figure 5(a)). The BSRI and EARI were also positive at this time (Table 5). Additionally, weak positive height anomalies were located over all three regions during the ten-day period before the extreme heat (Figure 5(b)). Note that in Figures 5(a) and 5(b), the positive height anomalies are located further poleward than those during the two cold season case studies discussed above. Nonetheless, this represented a successful forecast by both indexes for positive anomalies and a warm weather case.

4.4. Discussion. In this work, the BSR and EAR are shown to be successful in forecasting anomalous $(2 \sigma)$ cold or warmth in the central USA using statistics during a 54-month test forecast period and case studies. While both the BSR and EAR showed skill over climatology using signal detection theory, only the BSR was able to extract signal from noise at statistically significant levels. Then, following previously published techniques, a BSRI and EARI were derived. The work of [17] quantified connections between the flow regime over the Pacific and North America using the $500 \mathrm{hPa}$ height fields and these have been noted qualitatively for a long time in the literature going back at least 75 years. As far back as 1940, [55] noted a negative correlation between sea level pressure in the Aleutian region and the western USA. Later, $[56,57]$ noted that there were strong correlations between the North Pacific and Eastern USA flow regimes.

Our analysis in Sections 3 and 4 showing strong correlations between blocking or the West Pacific Oscillation (WPO) and the temperature regime of the middle USA is not new. However, what is new is that Section 4 demonstrates that there may be utility in making forecasts for the continental USA in the two-to-four-week time frame using the PNA index as well as the BSRI and EARI especially for anomalous events. 


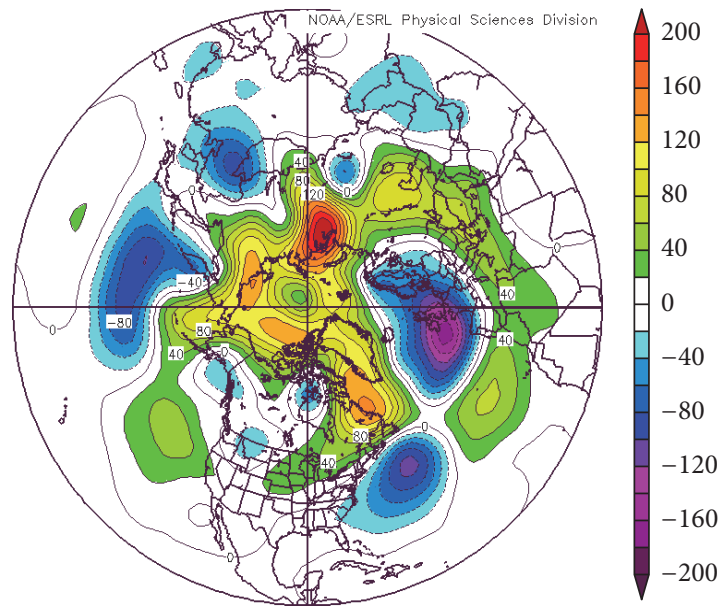

(a)

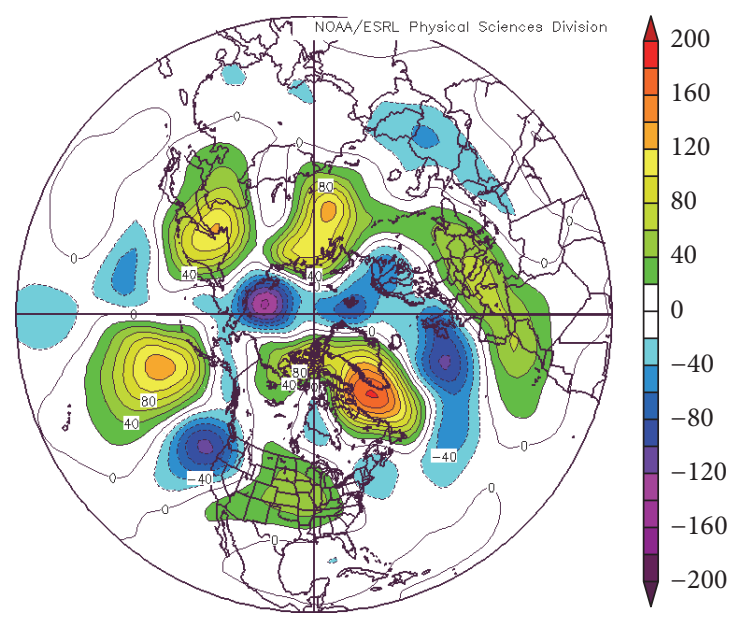

(b)

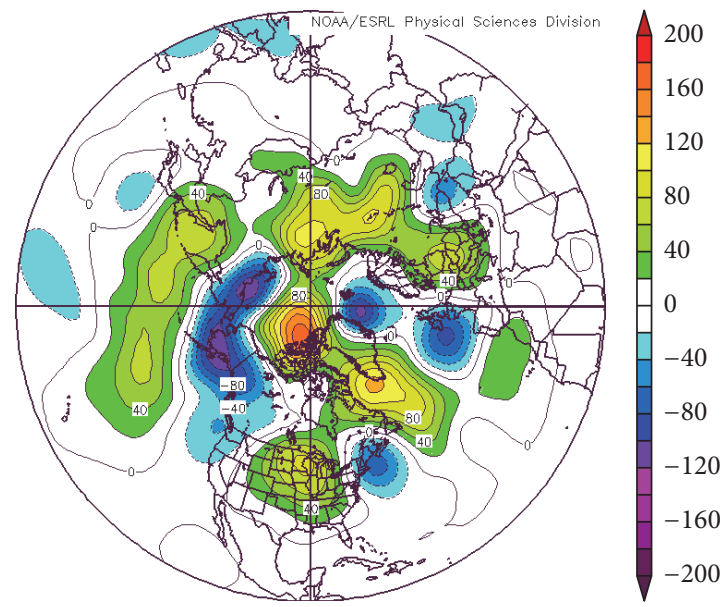

(c)

Figure 5: As in Figures 3(a), 3(b), and 3(c), except for (a) 6-16 June 2012, (b) 20-30 June 2012, and (c) 26 June-6 July 2012 and a contour interval of $20(\mathrm{~m})$.

As shown in Section 3, the PNA and WPO centers of action (derived from the $500 \mathrm{hPa}$ height field) showed a high correlation to Midwestern monthly temperatures similar to [29-32]. However, [18] demonstrated that the PNA centers of action are not always located in the same regions defined by [17] and more than four centers of action can be present. Also, Figures 6-8 show the track of Rossby waves propagation in the $500 \mathrm{hPa}$ height field using Hovmoller Diagrams, which are commonly used for identifying stationary features such as blocking; see [25, 26, 39]. Additionally, [45] demonstrated a Pacific Region wave train showing centers of action between East Asia and Bering Sea Region and North America. The East Asia and Bering Sea Regions are generally close to the location of the WPO and PNA centers of action identified in Section 4.1, respectively. There is also a teleconnection across the East Asia and Pacific Ocean Region found in the upper air temperature fields as well (e.g., $[47,58]$ ), purported to be the result of Rossby wave propagation. Thus, we are confident that there is a physical mechanism (quasistationary Rossby wave trains) that may be responsible for long-range predictability using a simple rule or index such as the BSRI (EARI) whose centers are near two positively correlated PNA centers (the north WPO and eastern PNA centers).

As shown in Section 2, the BSR and EAR do not show skill above climatology in day-to-day forecasting. It is also argued that climatology may be difficult to improve upon in longrange forecasts. A forecast made using the BSR and EAR for two to four weeks in advance would rely on the persistence of a Rossby wave train over the Pacific North American region in order to verify. The work of [39] demonstrated that the duration and strength of blocking events are correlated positively, as are these blocking characteristics to the strength of upstream developing cyclones. Thus, it is not surprising that, after the remnants of Nuri developed explosively, a preexisting weak blocking event intensified (characterized as "strong," blocking index was 4.12 using the [23] definition) which persisted for 12 days. The blocking event induced troughing and colder conditions over North America during November 2014 (e.g., [59]). Typhoon Nuri and the chain of events that followed during November may have set the flow 


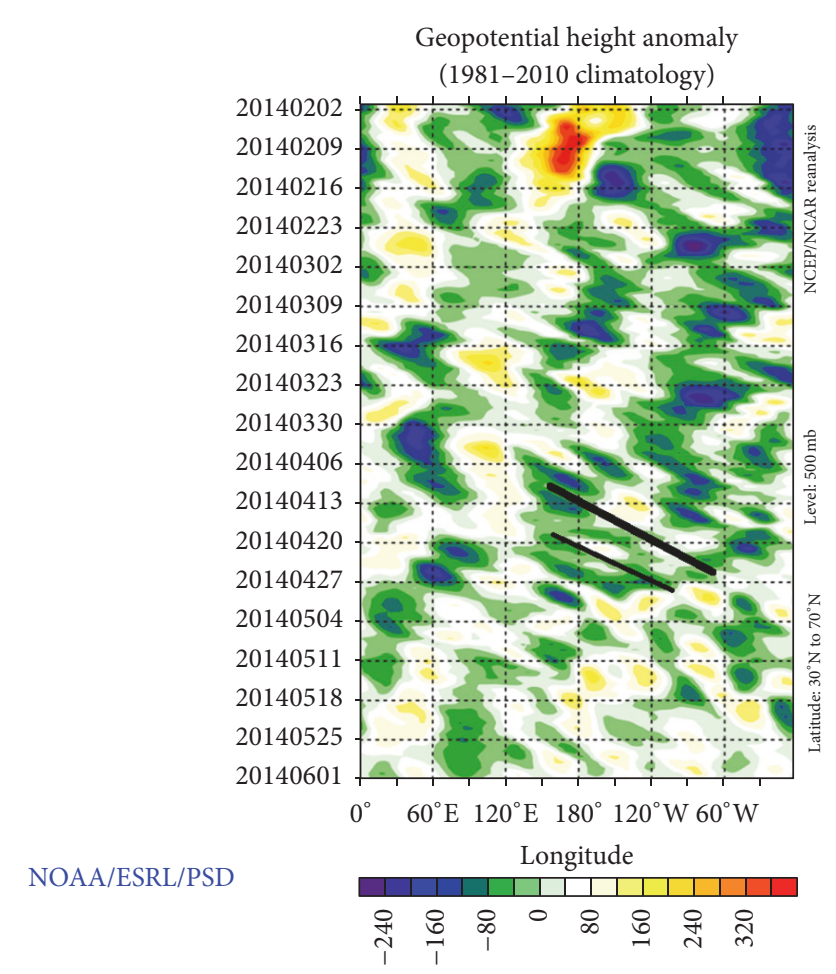

(m)

Figure 6: A time-longitude diagram for February-May 2014. The dark lines represent the possible path for the propagation of Rossby waves across the Pacific to North America via the BSR and EAR for the April 2014 case.

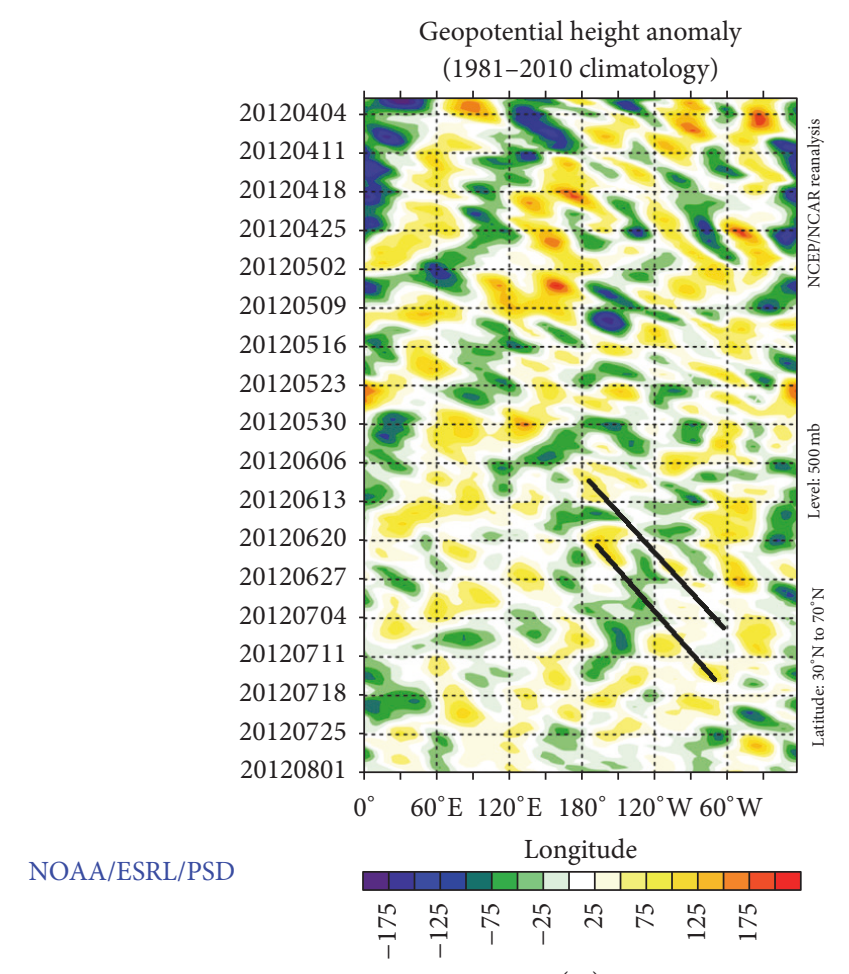

(m)

FIgURE 8: As in Figure 6, except for April-July 2012 and the summer heat case.

regime pattern for the entire winter of 2014-2015 over eastern North America $[52,60]$ which was colder than normal especially in the central USA and a harbinger of the repeat of a colder winter like 2013-2014 [24] for 2014-2015. In the Nuri case, this stronger, quasistationary, and more persistent flow regime over the PNA region can be attributed to the BSR(I) and EAR(I) success during November 2014. Additionally, the predictability of extreme warm conditions found using the BSR here is consistent with the results of anther recent study showing a 15-20-day PNA pattern that precedes US heat waves [61].

Thus, it is proposed here that a stronger and more persistent flow regime/Rossby wave train over the Pacific and North American region would be more conducive to the success of the BSR(I) and EAR(I) and that these indexes are useful for anticipating anomalous events. There is anecdotal evidence that these methods are being used successfully by forecasters in the private sector.

It was surprising that the EAR forecasts did not perform better that the BSR based forecasts based on the verification statistics. The BSR forecasts in the two-to-four-week time frame are beyond the realm of large-scale dynamic predictability $[7,8]$, while the bases for the EAR forecasts (one to two weeks) are on the edge of this time frame. The predictability of large-scale phenomena is generally accepted to be at 10-14 days. The EAR time frame is also close to the temporal predictability of blocking (e.g., [62]).
Figure 7: As in Figure 6, except for September to December 2014 and the Nuri case. 
However, a series of studies (e.g., [63-65]) demonstrated that the predictability of blocking could be somewhat successful beyond the limit of atmospheric dynamic predictability as long as the underlying surface (sea surface temperatures (SSTs)) was properly represented. This again suggests some predictability at longer time-scales or the time scale of the upper ocean. This same research group also demonstrated that the prevailing seasonal flow regimes as represented by height fields in the East Asia to North America region could be linked to Pacific Region SSTs (e.g., [31, 32]). This long-term predictability means that the BSR may outperform the EAR as was found here.

\section{Summary and Conclusions}

This study examined the utility of the BSR and EAR for extended outlooks in the 6-30-day time frame. Data sets archived at NOAA, NCEP/NCAR, and CPC were used primarily for this research. The results of this study are preliminary, and further work should be done in order to develop usable forecasting tools and a larger database gathered for the evaluation of forecast performance statistics. Additionally, the BSRI and EARI formulae were proposed for use here, and three case studies including these calculated index values were analyzed. As shown in Section 4, the BSRI (EARI) simply used two of the action centers from the PNA index (a WPO and PNA index action center) that correlated positively with centers in the USA in general.

Examining the skill for the EAR and BSR derived from the $500 \mathrm{hPa}$ height fields over a 15 -month period specifically in the 7-11- and 17-21-day period, respectively, showed that the results initially were consistent with climatology and neither rule showed skill in the classic sense. However, an examination of anomalous events ( $2 \sigma$ or greater) over a 54 month period encompassing the initial period demonstrated that both were able to forecast $2 \sigma$ temperature events in the upper Midwest. Thus, signal detection theory, similar to that typically used in synoptic and mesoscale meteorology, was used in order to test the efficacy of the BSR and EAR for detecting these extreme $2 \sigma$ events. Both methods demonstrated utility in identifying these anomalous temperature periods (POD); however the BSR was consistently higher (lower) in those measures associated with positive (negative) performance. The EAR scored higher in false alarm rate. While both outperformed climatology and the sensitivity index $\left(d^{\prime}\right)$ showed that only the BSR was able to extract signal from the noise at a statistically significant confidence level.

As expected, blocking in the North Pacific correlated strongly with teleconnections (the WPO) within ocean basins over a six-year period of study. While Atlantic Region blocking did correlate to central USA monthly temperature anomalies, Pacific Region blocking correlated more strongly (at the 99\% confidence level) and even correlated to monthly precipitation anomalies. As blocking is very difficult to forecast more than a day or two in advance (e.g., [23]), the occurrence of these events can result in monthly forecasts that are busted as evidenced during November 2014. The mid-October 30-day outlook projected normal to warm conditions for the central USA. Strong blocking in the early part of the month triggered by the remnants of Nuri led to the strong cold wave in the central USA persisting for the last two-thirds of the month.

In this study, the PNA index was used as a surrogate for the $500 \mathrm{hPa}$ height field in the Pacific Ocean and North America Region. Autocorrelation of two-year PNA time series from the period 1950-2016 showed cyclical behavior in the PNA time series (lagged by up to 130 days). This test suggested that there may be some predictability in the 16and 34-day time period, as well as a strong increase in the autocorrelation peaking beyond this from 35-70 days. Then, spectral analysis using 67 years of daily PNA index time series showed that there were identifiable peaks with a period of 24 and 21 days.

The predictability implied by the two tests is likely due to a long period Rossby wave as it propagates through the PNA region on a great circle trajectory (e.g., [66]). Here, three case studies were examined and showed about threeweek lag between a strong anomaly in the Bering Sea Region and severe weather or very cold or very warm weather over some portion of eastern two-thirds of the USA. In each case study, the BSRI identified conditions over the central USA successfully about three weeks in advance. Many studies have shown interaction between the longer-period PNA pattern and synoptic scale eddies (e.g., [67-69]). This is the scenario in the Typhoon Nuri case study. A simple index like the BSR or EAR, however, cannot take into account any changes in the intensity of the PNA pattern, nor can the index take into account periods when the PNA exists in an unusual phase or configuration (e.g., [18]). However, the BSR does have forecast skill for the occurrence of anomalous events above that of climatology, and a simple BSR and EAR Indexes (BSRI and EARI) were created for operational use by simply adding the height anomalies at the action centers. The use of any index such as the BSRI does include some interpretation by the forecaster, and more information about using the BSR and EAR operationally can be found at [70]. Finally, there is anecdotal evidence from contacts that these methods are being used successfully in the private sector.

\section{Conflicts of Interest}

The authors declare that they have no conflicts of interest.

\section{References}

[1] J. Anderson, H. Van Den Dool, A. Barnston, W. Chen, W. Stern, and J. Ploshay, "Present-day capabilities of numerical and statistical models for atmospheric extratropical seasonal simulation and prediction," Bulletin of the American Meteorological Society, vol. 80, no. 7, pp. 1349-1361, 1999.

[2] A. G. Barnston, A. Kumar, L. Goddard, and M. P. Hoerling, "Improving seasonal prediction practices through attribution of climate variability," Bulletin of the American Meteorological Society, vol. 86, no. 1, pp. 59-72, 2005.

[3] A. R. Lupo and P. S. Market, "The application of a simple method for the verification of weather forecasts and seasonal variations in forecast accuracy," Weather and Forecasting, vol. 17, no. 4, pp. 891-897, 2002. 
[4] A. R. Lupo and P. S. Market, "First conference on weather analysis and forecasting issues in the central United States," Bulletin of the American Meteorological Society, vol. 84, pp. 1245-1247, 2003.

[5] “Climate Prediction Center Long Range Forecasts," http://www .cpc.ncep.noaa.gov/products/predictions/long_range/seasonal .php?lead $=1$.

[6] "Climate Prediction Center 8-14 Day Forecasts," http://www.cpc .ncep.noaa.gov/products/predictions/814day/interactive/index .php.

[7] E. N. Lorenz, "Deterministic non-periodic flow," Journal of the Atmospheric Sciences, vol. 20, pp. 130-141, 1963.

[8] E. N. Lorenz, "A study of the predictability of a 28-variable model," Tellus, vol. 17, pp. 321-333, 1965.

[9] G. J. Haltiner and R. T. Williams, Numerical Prediction and Dynamic Meteorology, Wiley and Sons, Hoboken, NJ, USA, 2nd edition, 1980.

[10] D. R. Durran, Numerical Methods for Wave Equations in Geophysical Fluid Dynamics, Springer, New York, NY, USA, 1999.

[11] X. Zeng, R. A. Pielke, and R. Eykholt, "Estimating the fractal dimension and the predictability of the atmosphere," Journal of the Atmospheric Sciences, vol. 49, no. 8, pp. 649-659, 1992.

[12] A. R. Lupo, Y. C. Li, Z. C. Feng, N. I. Fox, J. L. Rabinowitz, and M. J. Simpson, "Sensitive versus rough dependence under initial conditions in atmospheric flow regimes," Atmosphere, vol. 7, no. 12, article no. 157, 2016.

[13] M. S. Tracton and E. Kalnay, "Operational ensemble prediction at the national meteorological center: practical aspects," Weather and Forecasting, vol. 8, no. 3, pp. 379-398, 1993.

[14] Z. Toth and E. Kalnay, "Ensemble forecasting at NCEP: the generation of perturbations," Bulletin of the American Meteorological Society, vol. 74, pp. 2317-2330, 1993.

[15] Z. Toth and E. Kalnay, "Ensemble forecasting at NCEP and the breeding method," Monthly Weather Review, vol. 125, no. 12, pp. 3297-3319, 1997.

[16] "Climate Prediction Center," http://www.cpc.ncep.noaa.gov/ products/predictions/WK34/.

[17] J. M. Wallace and D. S. Gutzler, "Teleconnections in the geopotential height field during the Northern Hemisphere winter," Monthly Weather Review, vol. 109, no. 4, pp. 784-812, 1981.

[18] A. R. Lupo and L. F. Bosart, "An analysis of a relatively rare case of continental blocking," Quarterly Journal of the Royal Meteorological Society, vol. 125, no. 553, pp. 107-138, 1999.

[19] L. Ning and R. S. Bradley, "NAO and PNA influences on winter temperature and precipitation over the eastern United States in CMIP5 GCMs," Climate Dynamics, vol. 46, no. 3-4, pp. 12571276, 2016.

[20] J. A. Renwick and M. J. Revell, "Blocking over the South Pacific and Rossby wave propagation," Monthly Weather Review, vol. 127, no. 10, pp. 2233-2247, 1999.

[21] Y. Wang, X. Xu, A. R. Lupo, P. Li, and Z. Yin, “The remote effect of the Tibetan Plateau on downstream flow in early summer," Journal of Geophysical Research: Atmospheres, vol. 116, no. 19, Article ID D19108, 2011.

[22] R. S. Quiroz, "The climate of the 1983-84 winter - a season of strong blocking and severe cold in North America.," Monthly Weather Review, vol. 112, no. 9, pp. 1894-1912, 1984.

[23] J. M. Wiedenmann, A. R. Lupo, I. I. Mokhov, and E. A. Tikhonova, "The climatology of blocking anticyclones for the
Northern and Southern Hemispheres: block intensity as a diagnostic," Journal of Climate, vol. 15, no. 23, pp. 3459-3473, 2002.

[24] A. Marinaro, S. Hilberg, D. Changnon, and J. R. Angel, "The North Pacific-driven severe Midwest winter of 2013/14," Journal of Applied Meteorology and Climatology, vol. 54, no. 10, pp. 21412151, 2015.

[25] A. R. LUpo and P. J. Smith, "Planetary and synoptic-scale interactions during the life cycle of a mid-latitude blocking anticyclone over the North Atlantic," Special Issue: The Life Cycles of Extratropical Cyclones, vol. 47, no. 5, pp. 575-596, 1995.

[26] A. R. Lupo, "A diagnosis of two blocking events that occurred simultaneously in the mid-latitude Northern Hemisphere," Monthly Weather Review, vol. 125, no. 8, pp. 1801-1823, 1997.

[27] A. R. Lupo, E. P. Kelsey, D. K. Weitlich, N. A. Davis, and P. S. Market, "Using the monthly classification of global SSTs and 500 $\mathrm{hPa}$ height anomalies to predict temperature and precipitation regimes one to two seasons in advance for the mid-Mississippi region," Nat. Wea. Dig, vol. 32, pp. 11-33, 2008.

[28] A. R. Lupo, I. I. Mokhov, Y. G. Chendev, M. G. Lebedeva, M. Akperov, and J. A. Hubbart, "Studying summer season drought in Western Russia," Advances in Meteorology, Special Issue: Large Scale Atmospheric Science, vol. 2014, Article ID 942027, 9 pages, 2014.

[29] R. G. Newberry, A. R. Lupo, A. D. Jensen, and R. A. Zalipynis, "An analysis of the spring-to-summer transition in the west central plains for application to long range forecasting," Atmospheric and Climate Sciences, vol. 6, no. 3, pp. 375-393, 2016.

[30] M. J. Nunes, A. R. Lupo, M. G. Lebedeva, Y. G. Chendev, and A. B. Solovyov, "The occurrence of extreme monthly temperatures and precipitation in two global regions," Papers in Applied Geography, vol. 3, no. 2, pp. 143-156, 2017.

[31] E. C. Kung and J.-G. Chern, "Prevailing anomaly patterns of the global sea surface temperatures and tropospheric responses," Atmósfera, vol. 8, pp. 99-114, 1995.

[32] K. Birk, A. R. Lupo, P. E. Guinan, and C. E. Barbieri, “The interannual variability of midwestern temperatures and precipitation as related to the ENSO and PDO," Atmosfera, vol. 23, no. 2, pp. 95-128, 2010.

[33] H. E. Brooks, "Tornado - warning performance in the past and future: a perspective from signal detection theory," Bulletin of the American Meteorological Society, vol. 85, pp. 837-844, 2004.

[34] "National Oceanography and Atmospheric Administration, Severe Storm Probabilities," http://www.nws.noaa.gov/mdl/ scan/test2/awipssvr.htm.

[35] T. D. Wickens, Elementary Signal Detection Theory, Oxford University Press, Oxford, UK, 2001.

[36] N. Macmillan and C. Creelman, Detection Theory: A Users Guide. Taylor and Francis, vol. 512, Taylor and Francis, Abingdon, UK, 2004.

[37] “University of Missouri Blocking," http://weather.missouri.edu/ gcc.Archive.

[38] H. Athar and A. R. Lupo, "Scale and stability analysis of blocking events from 2002-2004: a case study of an unusually persistent blocking event leading to a heat wave in the Gulf of Alaska during August 2004," Advances in Meteorology, vol. 2010, Article ID 610263, 15 pages, 2010.

[39] A. R. LUPO and P. J. SMITH, "Climatological features of blocking anticyclones in the Northern Hemisphere," Tellus A: Dynamic Meteorology and Oceanography, vol. 47, no. 4, pp. 439456, 1995. 
[40] D. F. Rex, "Blocking action in the middle troposphere and its effect upon regional climate II. The climatology of blocking action," Tellus, vol. 2, no. 4, pp. 275-301, 1950.

[41] H. Lejenas and H. Okland, "Characteristics of Northern Hemisphere blocking as determined from a long time series of observational data," Tellus A: Dynamic Meteorology and Oceanography, vol. 35, no. 5, pp. 350-362, 1983.

[42] J. Neter, W. Wasserman, G. A. Whitmore, and G. A. Whitmore, Applied Statistics, Allyn and Bacon, Boston, Mass, USA, 3rd edition, 1988.

[43] A. Obraczka, "Computer Methods for Chaos Diagnostic," Automatyka, vol. 15, pp. 71-83, 2011.

[44] W. A. Brock, D. A. Hsieh, and B. LeBaron, Nonlinear Dynamics, Chaos, and Instability: Statistical Theory and Economic Evidence, MIT Press, Cambridge, Mass, USA, 1991.

[45] X. Jiang and N.-C. Lau, "Intraseasonal teleconnection between North American and Western North Pacific monsoons with 20day time scale," Journal of Climate, vol. 21, no. 11, pp. 2664-2679, 2008.

[46] Y. Wang and A. R. Lupo, "An extratropical air-sea interaction over the North Pacific in association with a preceding el Niño episode in early summer," Monthly Weather Review, vol. 137, no. 11, pp. 3771-3785, 2009.

[47] Y. Wang, A. R. Lupo, and J. Qin, "A response in the ENSO cycle to an extratropical forcing mechanism during the El Nino to La Nina transition," Tellus Series A: Dynamic Meteorology and Oceanography, vol. 65, Article ID 22431, 2013.

[48] B.-M. Kim, G.-H. Lim, and K.-Y. Kim, "A new look at the midlatitude-MJO teleconnection in the northern hemisphere winter," Quarterly Journal of the Royal Meteorological Society, vol. 132, no. 615, pp. 485-503, 2006.

[49] C. Cassou, "Intraseasonal interaction between the MaddenJulian Oscillation and the North Atlantic Oscillation," Nature, vol. 455, no. 7212, pp. 523-527, 2008.

[50] Q. Hu, C. M. Woodruff, and S. E. Mudrick, "Interdecadal variations of annual precipitation in the Central United States," Bulletin of the American Meteorological Society, vol. 79, no. 2, pp. 221-229, 1998.

[51] "Climate Prediction Center Long Range Forecast Archive," http://www.cpc.ncep.noaa.gov/products/archives/long_lead/ llarc.indphp.

[52] A. D. Jensen, "A dynamic analysis of a record breaking winter season blocking event," Advances in Meteorology, vol. 2015, Article ID 634896, 9 pages, 2015.

[53] J. S. Renken, J. Herman, D. Parker, T. Bradshaw, and A. R. Lupo, "Using the bering sea and typhoon rules to generate long range forecasts II. Case studies," Climate Prediction, Science and Technology Conference Digest, vol. 40, pp. 51-55, 2016, http://www.nws.noaa.gov/ost/climate/STIP/40CDPW/ 40cdpw-JRenken.pdf.

[54] J. E. Thornes and E. A. Proctor, "Persisting with persistence: The verification of Radio 4 weather forecasts," Weather, vol. 54, no. 10, pp. 311-321, 1999.

[55] R. A. Allen, R. Fletcher, J. Holmboe, J. Namias, and H. C. Willett, Report on an experiment in five-day weather forecasting, Massachusetts Institute of Technology and Woods Hole Oceanographic Institution, Mass, USA, 1940.

[56] J. Namias, "The great pacific anticyclone of winter 1949-50: a case study in the evolution of climatic anomalies," Journal of Meteorology, vol. 8, no. 4, pp. 251-261, 1951.
[57] E. N. Lorenz, "Seasonal and irregular variations of the Northern hemisphere sea-level pressure profile," Journal of Meteorology, vol. 8, no. 1, pp. 52-59, 1951.

[58] P. Zhao, Z. Cao, and J. Chen, "A summer teleconnection pattern over the extratropical Northern Hemisphere and associated mechanisms," Climate Dynamics, vol. 35, no. 2, pp. 523-534, 2010.

[59] I. Orlanski and J. Sheldon, "A case of downstream baroclinic development over western North America," Monthly Weather Review, vol. 121, no. 11, pp. 2929-2950, 1993.

[60] L. F. Bosart, P. P. Papin, A. M. Bentley, and B. J. Moore, "Large-scale antecedent conditions associated with 20142015 winter onset over North America and the impact on predictability," in Proceedings of the 28th Conference on Climate Variability and Change, pp. 10-15, New Orleans, LA, USA, 2016, https://ams.confex.com/ams/96Annual/webprogram/ Paper282256.html.

[61] H. Teng, G. Branstator, H. Wang, G. A. Meehl, and W. M. Washington, "Probability of US heat waves affected by a subseasonal planetary wave pattern," Nature Geoscience, vol. 6, no. 12, pp. 1056-1061, 2013.

[62] M. Matsueda, "Predictability of Euro-Russian blocking in summer of 2010," Geophysical Research Letters, vol. 38, no. 6, Article ID L06801, 2011.

[63] E. C. Kung, C. C. Dacamara, W. E. Baker, J. Susskind, and C. Park, "Simulations of winter blocking episodes using observed sea surface temperatures," Quarterly Journal of the Royal Meteorological Society, vol. 116, no. 495, pp. 1053-1070, 1990.

[64] E. C. Kung, W. Min, J. Susskind, and C. Park, "An analysis of simulated summer blocking episodes," Quarterly Journal of the Royal Meteorological Society, vol. 118, no. 504, pp. 351-363, 1992.

[65] E. C. Kung, J. Susskind, and C. C. Dacamara, "Prominent Northern hemisphere winter blocking episodes and associated anomaly fields of sea surface temperatures," Terrestrial, Atmospheric and Oceanic Sciences, vol. 4, no. 3, p. 273, 1993.

[66] B. J. Hoskins and D. J. Karoly, "The steady linear response of a spherical atmosphere to thermal and orographic forcing," Journal of the Atmospheric Sciences, vol. 38, no. 6, pp. 1179-1196, 1981.

[67] N. C. Lau, "Variability of the observed midlatitude storm tracks in relation to low-frequency changes in the circulation pattern," Journal of the Atmospheric Sciences, vol. 45, pp. 2718-2743, 1988.

[68] N. M. Hall and J. Derome, "Transience, nonlinearity, and eddy feedback in the remote response to El Niño," Journal of the Atmospheric Sciences, vol. 57, no. 24, pp. 3992-4007, 2000.

[69] G. Rivière and I. Orlanski, "Characteristics of the Atlantic storm-track eddy activity and its relation with North Atlantic Oscillation," Journal of the Atmospheric Sciences, vol. 64, no. 2, pp. 241-266, 2007.

[70] "Organic Forecasting," http://weather.kopn.org/. 

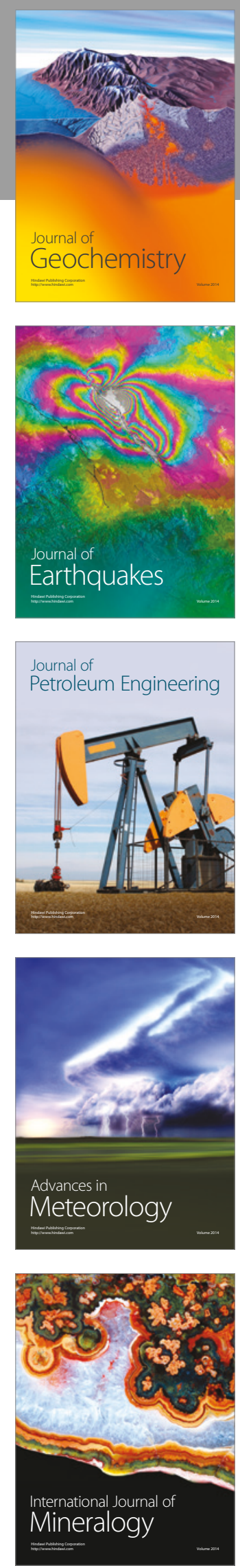
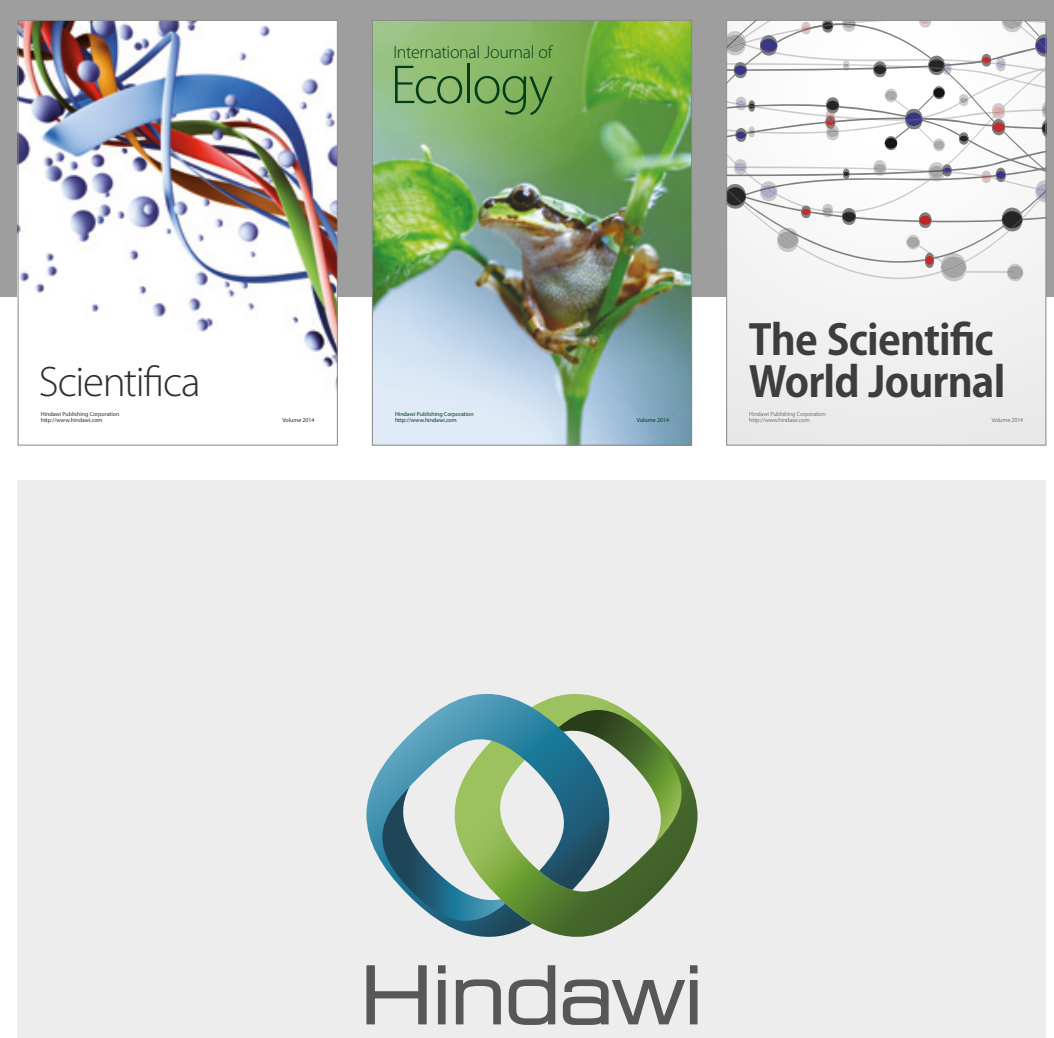

Submit your manuscripts at

https://www.hindawi.com
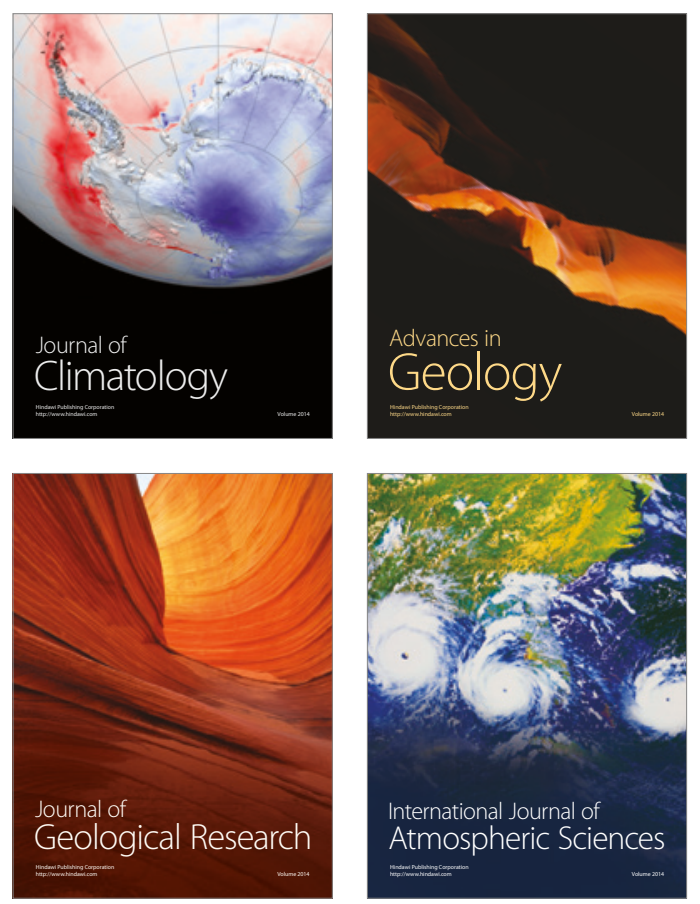

The Scientific

World Journal
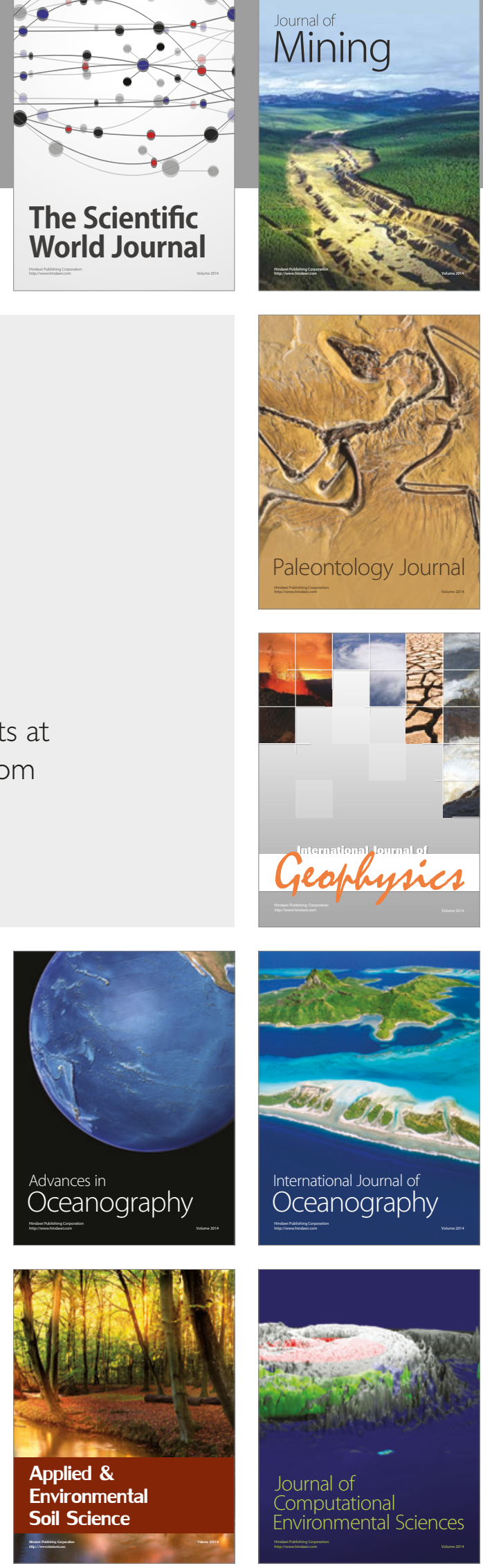